\title{
Forum
}

doi:10.1017/S0373463312000203

\section{Not Under Command}

\author{
Carlos F. Salinas ${ }^{1}$, Victoria Peña ${ }^{2}$, Gonzalo Pérez ${ }^{2}$ and Tricia L. Horton ${ }^{2}$ \\ 1 (Spanish Maritime Safety Agency) \\ (Email: fernandezsalinas@gmail.com) \\ ${ }^{2}$ (No current Affiliation)
}

\begin{abstract}
Vessels are found frequently operating under the Automatic Identification System (AIS) 'Not Under Command' (NUC) option near ports and close to shores in order to report their manoeuvre status to nearby traffic. When asked if they are under any kind of restriction regarding their engines or steering, they often answer that they are just drifting or waiting for the pilot or shipowner's orders. The question that arises is this: "Are these vessels really under an NUC situation or can the AIS Navigational Status menu adapt to the different circumstances of navigation?".
\end{abstract}

\section{KEY WORDS}

\section{COLREGs. 2. AIS. 3. VTS.}

Submitted: 27 February 2012. Accepted: 3 April 2012. First published online: 1 June 2012.

1. INTRODUCTION. A 'Not Under Command' (NUC) vessel is at the mercy of winds and seas. This not only puts her safety at risk but also the safety of other vessels sailing nearby. This is the reason why she is forced to report her situation. Some transmitted information has been recently added by the Automatic Identification System (AIS) along with the light and shape combinations that appear in the International Regulations for Preventing Collisions at Sea (COLREGs, 1972). Nevertheless, that numerous vessels use the NUC option of the Navigational Status Menu in an inaccurate way. This misunderstanding, whether deliberate or not, can confuse not only the Vessel Traffic Services (VTS) but also the rest of the ships sailing in the surrounding area.

2. NOT UNDER COMMAND SCENARIO. The COLREGs state in Rule 3(f):

The term "vessel not under command" means a vessel which through some exceptional circumstance is unable to manoeuvre as required by these Rules and is therefore unable to keep out of the way of another vessel. 


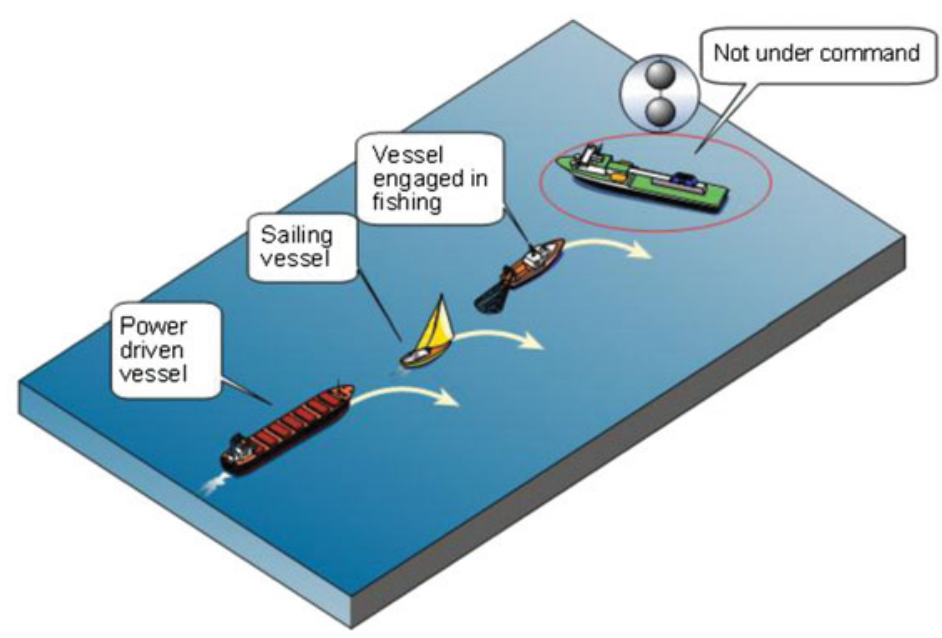

Figure 1. Responsibilities between vessels.

In the same way, the COLREGs make reference to this situation in Rule 18, to give privilege to power-driven vessels, sailing vessels, and vessels engaged in fishing, as long as they are within sight of each other, in the order shown at Figure 1.

However, Rule 27 determines the lights and shapes that all NUCs must exhibit (i.e., two red lights at night and two balls during the day). In addition to that, Rule 35 determines the sound signals to be used in conditions of restricted visibility (i.e., three blasts in succession, namely one prolonged followed by two short blasts), which is the same signal that has to be used by other vessels presenting any kind of restriction (i.e., sailing vessels, vessels engaged in fishing, vessels restricted in their ability to manoeuvre or vessels constrained by their draught).

3. NOT UNDER COMMAND IN PRACTICE. An important fact to be underlined is that if there is an accident where a vessel exhibits the NUC lights or shapes, that vessel will have to effectively prove that it was not qualified to carry out a manoeuvre to prevent the collision (see Figure 2). In this sense, the most illustrative case was ZIEMIA SZCZECINSKA versus DJEREDA, where both vessels collided in a crossing situation in the Strait of Dover in 1969. Specifically, DJEREDA, which had the ZIEMIA SZCZECINSKA on her starboard side, was sailing exhibiting its NUC lights, based on the fact that because of bad weather conditions she could not alter her course. Nevertheless, after hearing both sides, the Court did not accept the DJEREDA to be in a NUC situation, as it was shown that DJEREDA was sailing at more than 6 knots, with full use of her engines and steering at that time. For that reason DJEREDA was declared responsible and sentenced to pay $3 / 5$ ths of the damages (UK Court of Appeal, 1976).

Among the different circumstances a Court of Law accepts for a vessel to be in a NUC situation are the following:

- A breakdown of engines or steering gear.

- The loss of the propeller or the rudder.

- A sailing vessel becalmed (as long as she does not have an engine). 


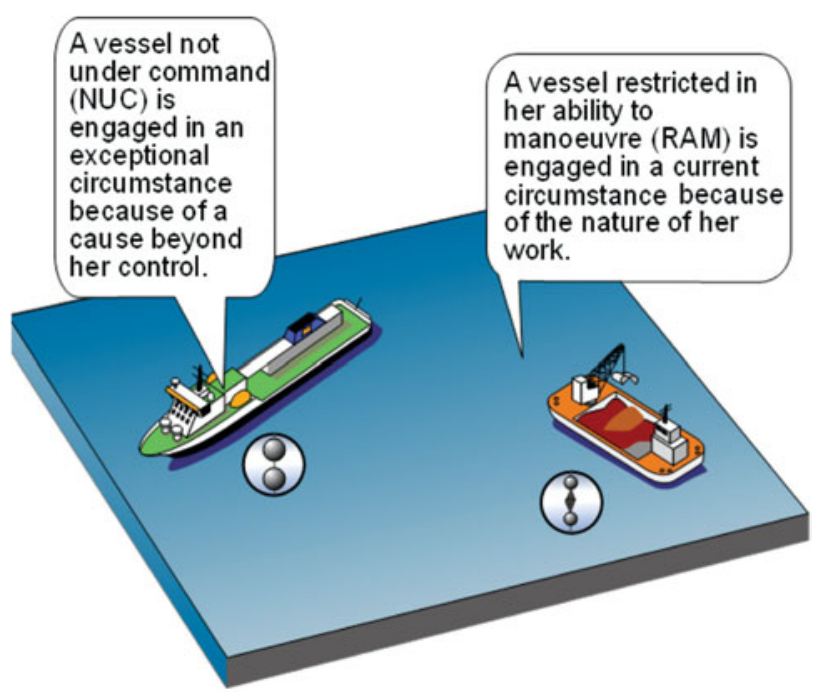

Figure 2. Differences between NUC and RAM.

- A vessel with her anchor down but not holding.

- Exceptional weather conditions (we emphasize here the importance of the adjective "exceptional").

\section{NOT UNDER COMMAND VERSUS RESTRICTED IN HER} ABILITY TO MANOEUVRE. A quite frequent misunderstanding consists of confusing a NUC situation with a vessel which is 'Restricted in her Ability to Manoeuvre' (RAM). In this sense Rule 3(g) states:

The term "vessel restricted in her ability to manoeuvre" means a vessel which from the nature of her work is restricted in her ability to manoeuvre as required by these Rules and is therefore unable to keep out of the way of another vessel.

That is, whereas a NUC situation is exceptional and unwanted, it is, however, a normal situation for a RAM vessel because the nature of her work leads to it (see Figure 2).

Rule 3(g) explains this in detail, by further stating:

The term "vessels restricted in her ability to manoeuvre shall include but not be limited to:

(i) a vessel engaged in laying, servicing or picking up a navigation mark, submarine cable or pipeline;

(ii) a vessel engaged in dredging, surveying or underwater operations;

(iii) a vessel engaged in replenishment or transferring persons, provisions or cargo while underway;

(iv) a vessel engaged in launching or recovery of aircraft;

(v) a vessel engaged in mine clearance operations;

(vi) a vessel engaged in a towing operation such as severely restricting the towing vessel and her tow in their ability to deviate from their course. 
However, if a vessel wants to demand 'RAM' priority over other vessels, any such vessel must be operating as specified in Rule 3(g). If, for instance, a 'dredger' is sailing from one port to another without actually carrying out dredging operations, the COLREGs will only consider her to be an ordinary power driven vessel, not a RAM vessel. We want to highlight that this is another basic difference between NUC and RAM vessels: NUC vessels have to stay in this situation until the problem is solved, but a RAM vessel can freely choose when she is going to operate as one and, if necessary, she can delay or even cancel the commencement of working (e.g., in the case of adverse weather conditions). It also has to be mentioned that the COLREGs do not include fishing vessels or sailing vessels as RAM vessels, as it considers these vessels to be in a better condition to start an escape manoeuvre, as stated in Rules 18 (b)/18(c). It is to be remembered that Rules 11 to 18 only apply when the vessels are within sight of each other, because in conditions of restricted visibility, Rule 19 applies instead and makes no distinction between vessels; the differences between categories of vessels fade to the point that Rule 35(c) demands all vessels with some kind of restriction make the same sound signal. The COLREGs do not specifically mention AIS, Very High Frequency (VHF) radio or Vessel Traffic Services (VTS). The arrival of AIS in particular demands an urgent revision of the COLREGs, particularly those of Part B 'Steering and Sailing Rules' (Rules 4 to 19 inclusive) to include some reference to this important new facility.

5. NOT UNDER COMMAND VERSUS UNDERWAY. Rule 3(i) of the COLREGs) states that:

The word "underway" means that a vessel is not at anchor, or made fast to the shore, or aground.

Although it may seem an obvious definition, different interpretations have originated to the point that the Maritime Safety Committee (MSC) of the International Maritime Organization (IMO) has issued further guidance to make some aspects clear in order to find a homogeneous interpretation of the concept. It has been made clear that a stopped vessel with no engine or steering problems is considered to be an underway vessel (IMO, 1982). This means that a vessel drifting with no other apparent problem shall have her engines ready to manoeuvre, and in case a risk of collision may happen, she is forced to respect the full Rules. Logically, and under such circumstances, a vessel shall not exhibit NUC lights and shapes, but instead those stated in Rule 23 , because the term 'underway' includes when the vessel is 'making way through water' but also when it is 'making no way through water' (as stated in Rule 35(a) and 35(b). That is, 'underway' is not a synonym for 'making way' (a typical misunderstanding of a non-English speaking mariner) but a hierarchically higher concept which includes the possibility or not of the use of the engine (see Figure 3).

6. AIS NAVIGATIONAL MENU. Although it is true that Regulation 19 of Chapter $\mathrm{V}$ of the International Convention for the Safety of Life at Sea (SOLAS) states the necessity of fitting an AIS, the technical and operational standards are ruled by a number of different guidelines and IMO recommendations (IMO, 1998; 2001), in 


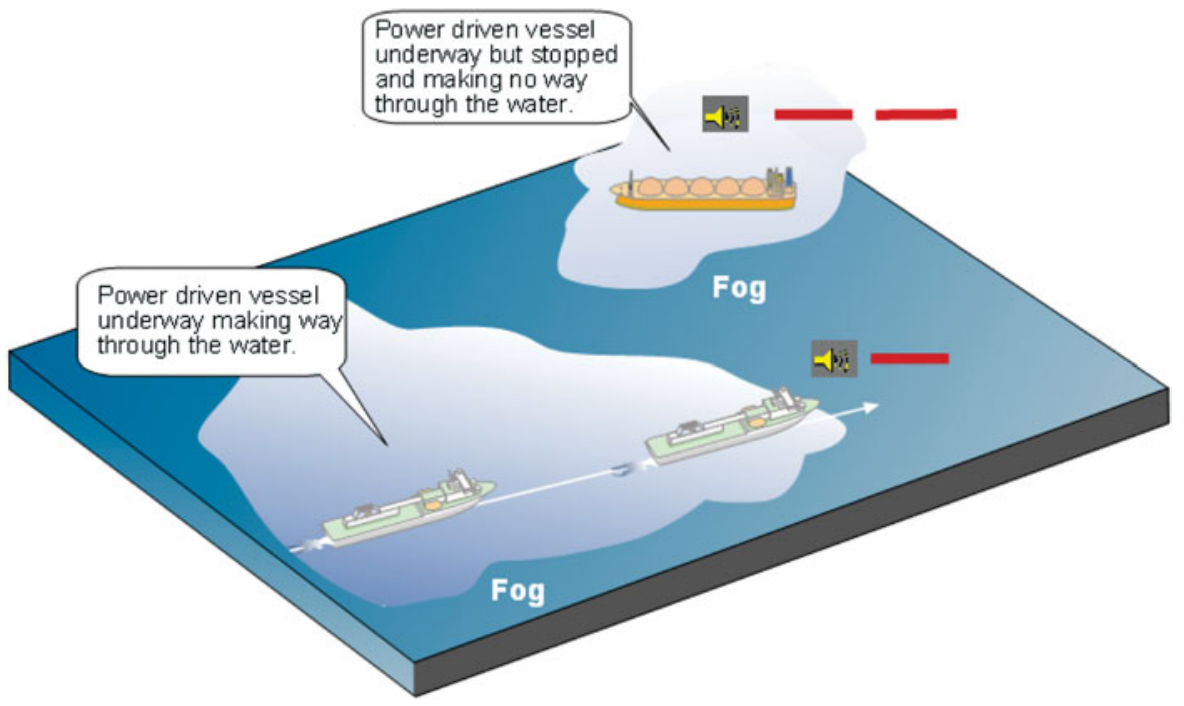

Figure 3. 'Underway' is not a synonym for 'making way' but a hierarchically higher concept that includes the use or not of the engine.

\section{Navigational Status Options}

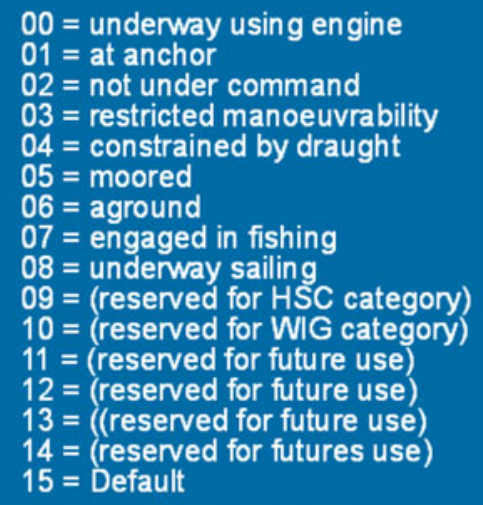

Figure 4. Navigational Status Menu.

addition to those of the International Telecommunication Union (ITU), the International Association of Marine Aids to Navigation and Lighthouse Authorities (IALA) and the International Electrotechnical Commission (IEC) (ITU, 2001; IALA, 2004; IEC, 2001). Following these criteria, the AIS 'Navigational Status' menu offers seafarers a number of fixed options to report their navigation state to the traffic and maritime authorities (see Figure 4) and, among others, it gives vessels the opportunity to choose the 'underway using engine' option. Nevertheless, when a vessel is drifting, for a lot of seamen this option does not exactly make reference to their current manoeuvre state, because at those moments the engine is not being used. This is the reason why most of them prefer choosing the AIS 'NUC' option. However, as has 
already been explained, a drifting vessel with her engines and steering in perfect working condition can never be considered to be in a NUC situation. Moreover, if we add that the different options of the AIS 'Navigational Status' menu are related to the COLREGs, and both IMO and IALA recommend that the option chosen in AIS has to be in accordance with the lights and shapes that the vessel is exhibiting, paradoxically, it is found that the AIS option to be chosen is 'underway using engine', and we state this for two reasons: Firstly, because as it has already been highlighted that the Rules consider a drifting vessel to be an underway vessel. Secondly, because although the vessel may not be using her engine, it is her duty to have it ready in case it should be needed to avoid a collision. To sum up, except if the officer on watch could not start the engine (for instance, when some repairs are being carried out), the vessel will be considered 'underway'. It must be understood that the expression 'using engine' means not only the effective use of the engine but also the possibility to start it at any given time.

7. PROPOSAL AS A CONCLUSION. On many occasions, mariners consider that rules and laws do not fit the real needs they have on-board. The fact that they are the first users of vessels gives them moral authority to disagree and demand some specific changes. However, no responsible seaman can avoid the fact that until those changes are made, the established rules must be respected. As the AIS 'Navigational Status' menu has a number of blank options (specifically from 11 to 14) which are reserved for future use, we recommend introducing a modification that could allow the user to choose a new option stating 'underway but engine stopped'. In this sense, the seafarer would have an alternative option without contradicting the COLREGs, because this expression is already included in the COLREGs.

\section{REFERENCES}

COLREGs (1972). International Regulations for Preventing Collisions at Sea 1972, with amendments adopted from December 2009. IMO Publications, London.

IALA [International Association of Marine Aids to Navigation and Lighthouse Authorities] (2004). Guideline on the Automatic Identification System (AIS), IALA Guideline No. 1028, Volume 1, Part I Operational Issues.

IEC [International Electrotechnical Commission] (2001). Maritime Navigation and Radio Communication Requirements - Automatic Identification Systems (AIS), IEC 61993-2 Ed.1.

IMO [International Maritime Organization] (1982), Guidance for the Uniform Application of Certain Rules of the 1972 Collision Regulations, IMO MSC Circular 332. IMO Publications, London.

IMO [International Maritime Organization] (1998). Recommendation on Performance Standards for an Universal Shipborne Automatic Identification Systems (AIS) IMO Resolution MSC.74 (69), Annex 3. (http://www.navcen.uscg.gov/pdf/marcomms/imo/msc_resolutions/MSC69-22a1-12.pdf).

IMO [International Maritime Organization] (2001). Guidelines for the Onboard Operational use of Shipborne Automatic Identification Systems IMO Resolution A.917 (22), as amended by resolution A.956(23). (http://www.navcen.uscg.gov/pdf/AIS/IMO_A_917(22)_AIS_OPS_Guidelines.pdf).

ITU [International Telecommunication Union] (2001). Technical Characteristics for a Universal Shipborne Automatic Identification System Using Time Division Multiple Access in the Maritime Mobile Band, ITU-R Recommendation M.1371-1.

UK Court of Appeal (1976). Case of ZIEMIA SZCZECINSKA versus DJEREDA, Lloyd's Law Report $1976, \mathbf{1}, 53$. 